\title{
Impact of COVID-19 Infection Threat on Chinese Consumer's Ding Behaviors in Restaurant after Work Resumption
}

\author{
Zhou An \\ Graduate School of Business, Segi University, Petaling Jaya, Malaysia \\ Email: anzhou4166@gmail.com
}

How to cite this paper: An, Z. (2021). Impact of COVID-19 Infection Threat on Chinese Consumer's Ding Behaviors in Restaurant after Work Resumption. Open Journal of Social Sciences, 9, 198-211. https://doi.org/10.4236/jss.2021.91014

Received: December 10, 2020

Accepted: January 16, 2021

Published: January 19, 2021

Copyright ( 2021 by author(s) and Scientific Research Publishing Inc. This work is licensed under the Creative Commons Attribution International License (CC BY 4.0).

http://creativecommons.org/licenses/by/4.0/

\section{(c) (i) Open Access}

\begin{abstract}
The outbreak of the Coronavirus Disease 2019 (COVID-19) has caused serious losses to catering industry. Even after the work resumption, the infection threat of the pandemic persistently affects consumers. This study aims to investigate the impact of COVID-19 infection threat on Chinese consumers' dining behaviors in restaurants after work resumption. Quantitative research methods were adopted to explore the relationship between infection threat and consumer behavior. Data were collected by distributing questionnaires to consumers in 4 restaurants in mainland China. A total of 190 valid questionnaires were received and then imported into SPSS software for analysis. The results indicate that the infection threat of COVID-19 is significantly related to consumer's behaviors, including contact limitation time optimization, keeping distance, personal security and dietary health. Consumers who perceive the infection threat consciously take actions to avoid risks while dining in restaurants. This study enriches literatures on the impact of the epidemic infection threat on consumer behavior. The findings imply that restaurants can reduce the consumer's concern of infection threat by changing the business mode, so that people can eat in restaurants without any anxiety.
\end{abstract}

\section{Keywords}

Coronavirus (COVID-19), Impact of Pandemic, Consumer Behavior, Restaurant

\section{Introduction}

COVID-19 has spread rapidly across the world since it outbreaks at the beginning of 2020. The pandemic has affected all walks of life in most countries and has a significant influence on the development of the world economy, among which the catering industry has been strongly impacted (Kashif, Aziz-Ur-Rehman, \& Javed, 
2020). In China, restaurants all over the country have been prohibited to provide dine-in services since January 25, 2020, which not only leads to significant loss of operating income on restaurants, but also leaves restaurant exposed to the fixed costs of labor and rental as well as the purchasing costs of materials for the disease prevention and control ( $\mathrm{Wu}, 2020)$. Although some restaurants provide takeout services during the outbreak, their financial positions have not improved markedly due to the reduction of orders, community's strict control on food delivery men and the increase of commission fees charged by the online delivery platform (Li, 2020).

As governments earnestly execute the prevention work and people consciously comply with the control measures, the COVID-19 epidemic has been effectively contained in many countries, including China, which results in the gradual resumption of economic activities. However, compared with the previous epidemics, the influences of COVID-19 on the way people live is quite different, owing to its characteristics of long incubation, strong infectiousness and wide spread. With the removal of social restrictions, the willingness of the public to continue to follow the prevention and control measures would be different from the severe period of the pandemic as the time goes by. In addition, according to the statement of World Health Organization (WHO), COVID-19 will coexist with human beings for a long time, which will continuously affect the behavior and habit in daily life (Cascella, Rajnik, Cuomo, Dulebohn, \& Di Napoli, 2020). Restaurant has always been an important place for people to eat, rest and socialize (Margetis, Grammenos, Zabulis, \& Stephanidis, 2013). But the relatively closed environment makes restaurant a potential site for virus transmission ( $\mathrm{Lu}$ et al., 2020). In order to avoid risk, consumer's behavior may differ under the continuous infection threat of COVID-19. Previous literatures mainly focus on personal protective motivation and preventive measures rather than consumer behavior during the epidemic (Norman, Boer \& Seydel, 2005; Mosler, 2012; Sharifirad, Yarmohammadi, Sharifabad, \& Rahaei, 2014). Due to the relatively short duration of previous pandemic (SARS, H1N1, etc), study on consumer behavior after work resumption is limited. Besides, the health protection behaviors of the public vary in different stages of epidemic (Wong and Sam, 2010). Therefore, it is necessary to investigate consumer's dining behavior in restaurant under the infection threat of COVID-19. This article aims to explore the impact of infection threat of COVID-19 on Chinese consumer's dining behavior in restaurant in the context of work resumption. Information is collected from consumers dining in restaurants through field survey and quantitative method is adopted to analyze the data.

\section{Research Framework and Hypothesis Development}

Studies conducted by researchers provide evidence that the infection threat of COVID-19 affects people eating in restaurants (He \& Harris, 2020; Cappelli \& Cini, 2020). For instance, people reduced the visit to restaurant and used con- 
tactless payment instead of cash (Kashif et al., 2020; Belarmino, Bertmann, Wentworth, Biehl, Neff, \& Niles, 2020a; Liu, Pan, \& Yin, 2020). As it turns out, when encountering threats, people are primarily motivated to take preventive measures to reduce the threat that comes with a lack of action (Gamma et al., 2017). Thus, the continuous COVID-19 epidemic is expected to have a significant impact on consumers' dining behavior in restaurants.

This study employs the framework of in-store epidemic behavior (Szymkowiak et al., 2020b), which explains the impact of the epidemic infection threat on consumer shopping behaviors. For this study, contact limitation, time optimization, keeping distance, personal security and dietary health are selected as factors to analyze the impact of COVID-19 infection threat on consumer dining behavior in restaurant.

\subsection{Infection Threat and Contact Limitation}

The perceived infection threat leads to the reduction of contact. In the past people shared tables in bars and restaurants to build relationships through food and drink. However, this trend is likely to run out (Ranka, 2020). Wang (2003) found that Chinese consumers changed previous habit of dining together and used individual portion to avoid infection caused by shared utensils during SARS. In one study on the impact of COVID-19 on food retail and food services in Cana$\mathrm{da}$, the results also showed that consumers tend to go to restaurants with fewer people to reduce contact with others during the epidemic (Goddard, 2020). Besides, Beijing Centers for Disease Control recommended people eat alone and reduce gatherings in restaurants after returning to work. Based on the foregoing arguments, the following hypothesis is proposed.

Hypothesis 1: Infection threat has positive impact on contact limitation.

\subsection{Infection Threat and Time Optimization}

The time optimization discussed in this article refers that people consciously reduce the length of stay in one place, limit personal exposure to strangers, and avoid peak hour, which includes not only quick actions but also unwillingness to talk with other people. A study by Sadique et al. (2007) found that in order to reduce the risk of infection, about $60 \%$ of the respondents reported that they only buy daily necessities while shopping. Shawa, Kim and Hua (2020) discovered that citizens in the Middle East tended to travel during off-peak periods to reduce the possibility of the virus spreading from person to person. In addition, a similar situation in a survey of Korean people was noticed (Nielson, 2020), as consumers changed their travel plans in order to avoid crowds. Taking these considerations together, the following hypothesis is proposed.

Hypothesis 2: Infection threat has positive impact on time optimization.

\subsection{Infection Threat and Keeping Distance}

Since COVID-19 spreads through close contact with other people, isolation has 
been considered as the most effective preventive measures, including isolation, quarantine, social distancing and community containment (Farooq, Laato, \& Islam, 2020; Wilder-Smith \& Freedman, 2020). Although isolation inevitably causes a lot of inconvenience, the threat of infection forced people to consciously comply with these measures (Rubin, Amlôt, Page, \& Wessely, 2009). Lee, Song, Bendle, Kim and Han (2012) found that people tried their best to reduce the infection risk by keeping distance from suspicious people and places during the H1N1 influenza. Apart from that, the perceived severity of the epidemic also affect people's intention to adopt social distancing (Sharifirad, Yarmohammadi, Sharifabad, \& Rahaei, 2014). Therefore, the following hypothesis is proposed.

Hypothesis 3: Infection threat has positive impact on keeping distancing.

\subsection{Infection Threat and Personal Security}

In accordance with the suggestion presented by $\mathrm{WHO}$ and national institutions, the personal hygiene measures include: 1) Washing hands frequently after reaching out other people or objects; 2) Wear masks in the public places; 3) Cover cough or sneeze with disposable tissue or clothes (Cascella, Rajnik, Cuomo, Dulebohn, \& Di Napoli, 2020). The emergence of epidemic allows the public to recognize the importance of personal hygiene and infection control (Iyengar, Mabrouk, Jain, Venkatesan, \& Vaishya, 2020). In Hong Kong, the widely adopted public's precautionary behaviors as well as early government interventions can contribute to the relative success of COVID-19 transmission control. The citizens of Hong Kong consciously took the responsibility for infection control and highly valued the individual prevention measures (Kwok et al., 2020). Besides, the contactless payment is recommended as it can reduce the chance of viral transmission. In China, Alipay and WeChat, two mobile applications that are most widely used, have become the first choice for people to conduct electronic transactions (Kupferschmidt \& Cohen, 2020). Electronic payments are also very popular in other countries during the epidemic, and the most favorite are credit and debit cards (Simbolon \& Riyanto, 2020). Thus, the following hypothesis is proposed.

Hypothesis 4: Infection threat has positive impact on personal security.

\subsection{Infection Threat and Dietary Health}

Except keeping distance and hygiene protection, dietary health is also a way to protect oneself and others from COVID-19. Although there is no evidence that a balanced diet can prevent COVID-19 infection, maintaining a healthy diet is an important part of supporting a strong immune system (FAO, 2020). China abolished the bad habit of consuming wildlife to prevent the spread of the virus through wild animals (Chang, 2020). In the aspect of diet, more people prefer vegetables instead of meat to enhance physical fitness (Bertmann, Belarmino, Wentworth, Biehl, \& Neff, 2020b). Previous Study revealed that a balanced diet boosts the immune system against virus attack (Aman \& Masood, 2020). In ad- 
dition, the perceived infection threat lead consumers to pay attention to the food security, such as whether the materials are fresh and the chefs and waiters take preventive measures (Ranka, 2020). Therefore, the following hypothesis is proposed.

Hypothesis 5: Infection threat has positive impact on dietary health.

\section{Method}

This article adopts quantitative research method to study the impact of COVID-19 infection threat on Chinese consumers' behaviors dining in restaurants after work resumption. Information was collected by questionnaires and data was analyzed to find out whether the proposed hypotheses are in line with reality, so as to answer the research questions.

\subsection{Sampling}

The survey was conducted in the restaurants near the residence of author, Nanyang city, Henan province, China. The reasons are mainly as follows: 1) Since the city that author lives in borders Hubei province to the south and is about 400 kilometers, the local government quickly took actions and control measures after the outbreak of epidemic in Wuhan. The epidemic has a greater impact on people eating in restaurants as the catering industry resume work late. 2) Because the target group of this study is ordinary consumers, the area selected for survey is a commercial district, with 50 or so restaurants nearby, covering all walks of life, from workers, teachers to office workers. The convenience sampling method is employed to approach to participants in the area. Convenience sampling is a non-probability sampling method that is often used to obtain a preliminary estimate of the research without costing time or money to select a random sample. In order to control the influences of the size and menu of restaurants, the author finally chooses 4 small family restaurants. The capacities of 4 restaurants vary between 20 and 30 and menus are based on Chinese home-style cooking. In light of the author's observation, each restaurant was at least half full at meal time. These restaurants are open all day long, offering breakfast, lunch and dinner, and providing dine-in and delivery services. Prior to the start of the survey, consents of owners of the restaurants were obtained and employees were promised to help distribute questionnaires.

The estimated sample size was calculated by using the quotation:

$$
n=\left(z_{1-\alpha / 2}\right)^{2} \times p \times q / d^{2} .
$$

$n=$ Desired sample size;

$Z_{1-a / 2}=$ Critical value and a standard value for the corresponding level of confidence;

$p=$ Expected prevalence or based on previous research;

$q=1-p$

$\mathrm{d}=$ Margin of error or precision. 
$10 \%$ margin of error and $95 \%$ confidence interval with $50 \%$ prevalence was considered for calculation (Chehab et al., 2019). A total 200 participants were recruited for this study.

\subsection{Data Collection}

The sample size of the study is 200 , with an average of 50 participants per restaurant. After reviewing relevant data collection tools from the literature, questionnaire items are developed by revising the in-store epidemic behavior scales by Szymkowiak et al. (2020a) as well as Prasetyo et al.'s (2020) questionnaire. The self-administered questionnaire is formulated in Chinese to collect participants' data. Table 1 shows the complete list of statements. The questionnaire consists of close-ended questions and participants are asked to rate the statements on a 5-point Likert scale. Based on the past experiences, the best period for survey is at noon or evening, as most people are in a hurry at breakfast time with low willingness to participate. The survey was conducted in early June, and 4 individuals collected data in 4 restaurants respectively. The purpose of the research was explained to customers dining behavior in restaurant, and questionnaires were handed out to participants. The restaurant coupons were distributed as gifts to those who filled the questionnaires.

\subsection{Data Analysis}

The questionnaires were taken back on the spot after all the participants filled them out and then were carefully checked. Excluding 7 incomplete questionnaires and 3 questionnaires with obvious mistakes, a total of 190 out of 200

Table 1. Factor statement.

\begin{tabular}{|c|c|}
\hline Factor & Item \\
\hline \multirow{3}{*}{ Contact Limitation (CL) } & Eating alone in restaurant (CL1) \\
\hline & Eating in a restaurant in which there are few people (CL2) \\
\hline & Not sharing food with others in restaurant (CL3) \\
\hline \multirow{2}{*}{ Time Optimization (TO) } & Reduce the length of stay in restaurant (TO1) \\
\hline & Eating in restaurant during off-peak hours (TO2) \\
\hline \multirow{3}{*}{ Keeping Distance (KD) } & Maintaining distance while waiting in line (KD1) \\
\hline & Sitting in a separate place while eating (KD2) \\
\hline & Not sitting opposite to others (KD3) \\
\hline \multirow{3}{*}{ Personal Security (PS) } & Keep wearing mask except mealtime (KD3) \\
\hline & Disinfecting after touching (PS1) \\
\hline & Using contactless payment (PS2) \\
\hline \multirow{3}{*}{ Dietary Health (DH) } & Purchasing food nutrition (PS3) \\
\hline & Eating balanced portion of vegetables and meat (DH1) \\
\hline & Focusing on restaurant food safety $(\mathrm{DH} 2)$ \\
\hline
\end{tabular}


questionnaires were available, for an effective questionnaire returns-ratio is $95 \%$. All the information collected from participants coded and data was imported to SPSS statistics version 20.0 for analysis.

Descriptive statistics were adopted to summarize the socio-demographic characteristics. Confirmatory factor analysis was used to evaluate the validity and reliability of measurements. Pearson correlation coefficient was used to test the correlation between the infection threat and consumer behavior. Multiple linear regression analysis is used to identify the influences of infection threat on consumers' dining behaviors.

\section{Result}

\subsection{Descriptive Statistics}

According to the results of the 190 Chinese consumers who participated in the survey, males account for $54.2 \%$ while females account for $45.8 \%$. In terms of age, 79 participants are from 21 - 30, 66 participants belong to the group age between 31 and 40, 33 participants aged from 41 - 50, and the rest of 12 participants belongs to the age range of 51 - 60. In the aspect of education level, more than $50 \%$ of participants have a college or bachelor degree, around $1 / 3$ of the participants have a high school degree, and the remaining participants has a master degree or above. In the respect of job, participants are mainly company employees, labors and retailers (Table 2).

Table 2. Participants profile.

\begin{tabular}{ccc}
\hline Characteristic & Frequency (n) & Percentage (\%) \\
\hline Gender & 103 & 54.2 \\
Male & 87 & 45.8 \\
Female & & \\
Age & 79 & 41.6 \\
$21-30$ & 66 & 34.7 \\
$31-40$ & 33 & 17.4 \\
41 - 50 & 12 & 6.3 \\
51 - 60 & & 30.0 \\
Education level & 57 & 55.3 \\
High school & 105 & 14.7 \\
College/Bachelor & 28 & \\
Master or above & & 23.2 \\
Job & 44 & 18.4 \\
Labor & 35 & 44.2 \\
Retailer & 84 & 9.5 \\
Company employee & 18 & 4.7 \\
Student & 9 &
\end{tabular}




\subsection{Confirmatory Factor Analysis}

The confirmatory factor analysis consists of 5 factors and 14 items. As the effective sample size for the analysis is 190 , which is 10 times more than the number of items, the sample size is moderate.

Table 3 shows that CFA results meet the recommended values $\left(\chi^{2} / \mathrm{df}=2.94\right.$, $\mathrm{GFI}=0.92$; CFI $=0.94, \mathrm{NFI}=0.93, \mathrm{IFI}=0.94, \mathrm{RMSEA}=0.076)$. On the whole, each scale has a significant level. All factors loading items are above 0.7 , indicating that there is a good correspondence between factors and the infection threat. To test the reliability of the scale, Cronbach's $\alpha$ is applied. The values of Cronbach's $\alpha$ range from 0.77 to 0.94 , representing good consistency. In addition, Composite Reliability (CR) and Average Variance Extracted (AVE) are used to test the convergent and discriminant validity. The AVE values are higher than the acceptable limit of 0.5 , with values ranging from 0.57 to 0.81 . The $C R$ values are between 0.74 and 0.92 , which exceeds the limit value of 0.7 . According to the above results, it can be assumed that the proposed research model has good validity, convergence and reliability.

\subsection{Correlation}

The mean value, standard deviation and Pearson correlation coefficient of the key factors are shown in Table 4.

From Table 4, it can be seen that contact limitation, time optimization, keeping distance, personal security and dietary health are positively related to infection threat. Among them, contact limitation $(r=0.74)$, keeping distance $(r$

Table 3. Results of confirmatory factor analysis.

\begin{tabular}{|c|c|c|c|c|c|c|}
\hline Factor & Item & Factor Loading & Sig. & Cronbach's a & $\mathrm{CR}$ & AVE \\
\hline \multirow{3}{*}{ Contact Limitation } & $\mathrm{CL} 1$ & 0.78 & $* *$ & \multirow{3}{*}{0.92} & \multirow{3}{*}{0.92} & \multirow{3}{*}{0.78} \\
\hline & CL2 & 0.92 & $* *$ & & & \\
\hline & CL3 & 0.89 & $* *$ & & & \\
\hline \multirow{2}{*}{ Time Optimization } & TO1 & 0.76 & $* *$ & \multirow{2}{*}{0.81} & \multirow{2}{*}{0.81} & \multirow{2}{*}{0.63} \\
\hline & TO2 & 0.72 & $* *$ & & & \\
\hline \multirow{3}{*}{ Keeping Distance } & KD1 & 0.95 & $* *$ & \multirow{3}{*}{0.94} & \multirow{3}{*}{$0.88-$} & \multirow{3}{*}{0.75} \\
\hline & KD2 & 0.88 & $* *$ & & & \\
\hline & KD3 & 0.90 & $* *$ & & & \\
\hline \multirow{3}{*}{ Personal Security } & PS1 & 0.84 & $* *$ & \multirow{3}{*}{0.90} & \multirow{3}{*}{0.90} & \multirow{3}{*}{$0.81-$} \\
\hline & PS2 & 0.88 & $* *$ & & & \\
\hline & PS3 & 0.83 & $* *$ & & & \\
\hline \multirow{3}{*}{ Dietary Health } & DH1 & 0.73 & $* *$ & \multirow{3}{*}{0.77} & \multirow{3}{*}{0.74} & \multirow{3}{*}{0.57} \\
\hline & $\mathrm{DH} 2$ & 0.76 & $* *$ & & & \\
\hline & DH3 & 0.72 & $* *$ & & & \\
\hline
\end{tabular}

${ }^{* *} p<0.01$. 
$=0.72)$ and personal security $(\mathrm{r}=0.79)$ are highly correlated with infection threat, time optimization $(r=0.62)$ is moderately correlated with infection threat, and dietary health $(\mathrm{r}=0.29)$ has a low correlation with infection threat.

\subsection{Linear Regression}

Table 5 reports the regression analysis results for hypotheses $1-5$, which focus on the impact of the infection threat of COVID-19 on the dining behaviors of consumers in restaurants.

Table 5 shows the impact of the infection threat on consumer behaviors, that is, the increased infection threat affects contact limitation $(\beta=0.47, p<0.01)$, time optimization $(\beta=0.25, p<0.05)$, keeping distance $(\beta=0.54, p<0.01)$, personal security $(\beta=0.46, p<0.01)$ and dietary health $(\beta=0.39, p<0.05)$. Thus Hypothesis $1 \sim 5$ are accepted.

The summary results of the hypothesis verification are shown in the Table 6 below.

Table 4. Pearson correlation coefficient.

\begin{tabular}{lcccccccc}
\hline \multicolumn{1}{c}{ Factor } & Mean & SD & $\mathbf{1}$ & $\mathbf{2}$ & $\mathbf{3}$ & $\mathbf{4}$ & $\mathbf{5}$ & $\mathbf{6}$ \\
\hline 1. Infection Threat & 4.07 & 1.17 & - & & & & & \\
2. Contact Limitation & 3.11 & 0.92 & 0.74 & - & & & & \\
3. Time Optimization & 4.14 & 1.04 & 0.62 & 0.36 & - & & & \\
4. Keeping Distance & 4.05 & 0.80 & 0.72 & 0.60 & 0.35 & - & \\
5. Personal Security & 4.36 & 0.65 & 0.79 & 0.61 & 0.26 & 0.65 & - \\
6. Dietary Health & 4.43 & 0.95 & 0.29 & 0.32 & 0.20 & 0.41 & 0.46 & - \\
\hline
\end{tabular}

Table 5. Model summary.

\begin{tabular}{|c|c|c|c|}
\hline Indicator & Latent Factor & Sig & Beta \\
\hline Infection Threat & Contact Limitation & ** & 0.47 \\
\hline Infection Threat & Time Optimization & * & 0.25 \\
\hline Infection Threat & Keeping Distance & ** & 0.54 \\
\hline Infection Threat & Personal Security & $* *$ & 0.46 \\
\hline Infection Threat & Dietary Health & * & 0.39 \\
\hline
\end{tabular}

${ }^{\star} p<0.05 ;{ }^{* *} p<0.01$.

Table 6. Hypothesis and result summary.

\begin{tabular}{lc}
\hline \multicolumn{1}{c}{ Hypothesis } & Accepted/Rejected \\
\hline H1: Infection threat has positive impact on contact limitation. & Accepted \\
H2: Infection threat has positive impact on time optimization. & Accepted \\
H3: Infection threat has positive impact on keeping distance. & Accepted \\
H4: Infection threat has positive impact on personal security. & Accepted \\
H5: Infection threat has positive impact on dietary health. & Accepted
\end{tabular}




\section{Conclusion}

\subsection{Discussion and Conclusion}

This study explores the influence of COVID-19 continuous infection threat on consumers' dining behaviors in restaurant. According to the calculation results, the infection threat of COVID-19 as a whole has a significant impact on behaviors of consumers eating in restaurant. As the infection threat exceeds the control of restaurants and customers, taking preventive measure is the only way to control the infection of COVID-19. This study verifies the conclusions of previous studies that people consciously take actions to reduce threats once the encounter risks (Hung et al., 2014; Janmaimool, 2017).

In this study, participants who perceived infection threat would limit contact with others (H1). Wen, Kozak, Yang, and Liu (2020) reported that most Chinese citizens use public chopsticks instead of shared utensils while dining in restaurants. Besides, since eating alone has become a common and positive phenomenon in China in recent years (Chio, Yang, \& Tabari, 2020), more people tend to eat alone in restaurants instead of gathering with others after work resumption. This is consistent with Rogers's (2020) view that eating alone is popular among family and friends during COVID-19. Participants also expressed their intention to optimize time in the restaurant (H2). Hayer (2020) observed that an increase of staggered shifts during the epidemic. Due to the infection risk, participants reported their actions to advance or postpone meal time to avoid peak hour. According to safety and health regulations of Traveltips (2020), people are suggested to reduce the length of stay in restaurant. It can be seen that many people follow the recommendations, reduce meal time and decrease the use of mobile phones while eating. In the aspects of keeping distance (H3) and personal security $(\mathrm{H} 4)$, previous researches indicate that personal preventive measures can reduce the threat caused by lack of action (Hung et al., 2014). Because of the vigorous publicity of the government and health organizations during the epidemic, people have a deeper understanding of public health knowledge. When dining out, consumers take the initiative to wash their hands with the disinfectant provided by the restaurant, keep wearing masks except meal time, and maintain a distance from others when queuing. In addition, the comprehensive constructions of China's information infrastructure make it possible for electronic payment services to be widely used in the consumer market (Lo, Li, \& Chan, 2019). Chinese consumers prefer to mobile payment in order to avoid infection. At last, this study found that the infection threat of COVID-19 makes people pay more attention to dietary health when eating in restaurants (H6). As healthy lifestyle contributes to strong immunity system which helps people avoid the spread of virus (Prasetyo, Castillo, Salonga, Sia, \& Seneta, 2020), the purchasing of dietary health is increasing.

\subsection{Implication and Limitation}

This study contributes to the exiting literature on consumer behavior. As dis- 
cussed before, there is little research on the impact of the continuous infection threat on consumers' dining behavior in restaurants after work resumption. This article explores the impact of infection threat of COVID-19 on consumers dining behaviors, which has certain practical significance for China's catering industry in the context of epidemic. Besides, this study also has managerial implications for restaurant owners. Regarding to contact limitation and time optimization, restaurants can provide a variety of single-serving meals and change business hours, so that customers can enjoy multiple flavors and avoid the crowds to eat. In terms of keeping distance and personal security, the addition of outdoor dining space not only benefits social distancing, but also contributes to the reception number. In addition, restaurants can provide disinfection measures such as hand sanitizer, and facilitate customers to pay by posting QR codes on tables or using portable code scanning machines, thereby reducing the number of people queuing to pay bills. Finally, owners of restaurants should pay attention to the nutrition and health of their menu, and truthfully respond to customers' concerns about the food safety.

There are some limitations in this study. Firstly, the sample selection may have a potential bias on hypothesis. The target population is Chinese consumers and survey is conducted in Nanyang city, Mainland China. However, consumers in different cities or regions of China may have different consumption habits, which limit the generality of the results. Secondly, the chosen convenience sampling adopted in this article may restrict us to make broader generalizations from the results. Thirdly, all of our data is obtained from self-reported survey questions, so our research results may have a common method variance problem. Finally, this study is limited to the catering industry in Mainland China, therefore the result may vary while applying to other industries or fields.

\section{Conflicts of Interest}

The author declares no conflicts of interest regarding the publication of this paper.

\section{References}

Aman, F., \& Masood, S. (2020). How Nutrition Can Help to Fight against COVID-19 Pandemic. Pakistan Journal of Medical Sciences, 36, (COVID19-S4). https://doi.org/10.12669/pims.36.COVID19-S4.2776

Belarmino, E. H., Bertmann, F., Wentworth, T., Biehl, E., Neff, R., \& Niles, M. T. (2020a). Early COVID-19 Impacts on Food Retail and Restaurants: Consumer Perspectives from Vermont. College of Agriculture and Life Sciences Faculty Publications, 24.

Bertmann, F., Belarmino, E. H., Wentworth, T., Biehl, E., Neff, R., \& Niles, M. T. (2020b). Food Access through School Meals and Food Pantries during COVID-19: Early Findings from Vermont. College of Agriculture and Life Sciences Faculty Publications, 22.

Cappelli, A., \& Cini, E. (2020). Will the COVID-19 Pandemic Make Us Reconsider the Relevance of Short Food Supply Chains and Local Productions? Trends in Food Science \& Technology, 99, 566-567. https://doi.org/10.1016/j.tifs.2020.03.041

Cascella, M., Rajnik, M., Cuomo, A., Dulebohn, S. C., \& Di Napoli, R. (2020). Features, 
Evaluation and Treatment Coronavirus (COVID-19). In Statpearls [Internet]. Treasure Island, FL: StatPearls Publishing.

Chang, J. (2020). Interpretation of the Decision of the Standing Committee of the National People's Congress of China to Abolish the Bad Habit of Consuming Wildlife Mindlessly. dA. Derecho Animal (Forum of Animal Law Studies), 11, 126-131. https://doi.org/10.5565/rev/da.497

Chehab, M. A., Nour, M., Bryant, G., Zahran, A., Al-Dahshan, A., Bala, M. O., AlKubaisi, N. J., \& Selim, N. A. (2019). Knowledge and Practice of Emergency Physicians Regarding Food-Borne Disease Surveillance at Hamad General Hospital in Qatar. Cureus, 11, e4934. https://doi.org/10.7759/cureus.4934

Choi, S. H., Yang, E. C. L., \& Tabari, S. (2020). Solo Dining in Chinese Restaurants: A Mixed-Method Study in Macao. International Journal of Hospitality Management, 90, 102628. https://doi.org/10.1016/j.ijhm.2020.102628

FAO (2020). Maintaining a Healthy Diet during the COVID-19 Pandemic. Rome: FAO.

Farooq, A., Laato, S., \& Islam, A. K. M. (2020). Impact of Online Information on SelfIsolation Intention during the COVID-19 Pandemic: Cross-Sectional Study. Journal of Medical Internet Research, 22, e19128. https://doi.org/10.2196/19128

Gamma, A. E., Slekiene, J., von Medeazza, G., Asplund, F., Cardoso, P., \& Mosler, H. J. (2017). Contextual and Psychosocial Factors Predicting Ebola Prevention Behaviours Using the RANAS Approach to Behaviour Change in Guinea-Bissau. BMC Public Health, 17, Article No. 446. https://doi.org/10.1186/s12889-017-4360-2

Goddard, E. (2020). The Impact of COVID-19 on Food Retail and Food Service in Canada: Preliminary Assessment. Canadian Journal of Agricultural Economics, 68, 1-5. https://doi.org/10.1111/cjag. 12243

Hayer, M. K. (2020). Evolution and Spread of Coronavirus throughout the World. International Journal of Humanities \& Social Science: Insights \& Transformations, 5, 23-36.

He, H., \& Harris, L. (2020). The Impact of COVID-19 Pandemic on Corporate Social Responsibility and Marketing Philosophy. Journal of Business Research, 116, 176-182. https://doi.org/10.1016/j.jbusres.2020.05.030

Hung, W. S., Hu, S. C., Hsu, Y. C., Chen, K. L., Chen, K. H., Yu, M. C., \& Chen, K. T. (2014). Factors Affecting the Use of Anti-Malaria Preventive Measures among Taiwan Immigrants Returning to Malaria-Endemic Regions. Travel Medicine and Infectious Disease, 12, 370-377. https://doi.org/10.1016/j.tmaid.2013.07.001

Iyengar, K., Mabrouk, A., Jain, V. K., Venkatesan, A., \& Vaishya, R. (2020). Learning Opportunities from COVID-19 and Future Effects on Health Care System. Diabetes \& Metabolic Syndrome, 14, 943-946. https://doi.org/10.1016/j.dsx.2020.06.036

Janmaimool, P. (2017). Application of Protection Motivation Theory to Investigate Sustainable Waste Management Behaviors. Sustainability, 9, 1079. https://doi.org/10.3390/su9071079

Kashif, M., Aziz-Ur-Rehman, \& Javed, M. K. (2020). Demystify the COVID-19 Effect on Restaurant. International Journal of Medical Science in Clinical Research and Review, 3, 281-289.

Kupferschmidt, K., \& Cohen, J. (2020). Can China's COVID-19 Strategy Work Elsewhere? Science, 367, 1061-1062. https://doi.org/10.1126/science.367.6482.1061

Kwok, K. O., Li, K. K., Chan, H. H., Yi, Y. Y., Tang, A., Wei, W. I., \& Wong, S. Y. (2020). Community Responses during Early Phase of COVID-19 Epidemic, Hong Kong. Emerging Infectious Diseases, 26, 1575-1579. https://doi.org/10.3201/eid2607.200500

Lee, C. K., Song, H. J., Bendle, L. J., Kim, M. J., \& Han, H. (2012). The Impact of 
Non-Pharmaceutical Interventions for 2009 H1N1 Influenza on Travel Intentions: A Model of Goal-Directed Behavior. Tourism Management, 33, 89-99.

https://doi.org/10.1016/j.tourman.2011.02.006

Li, J. (2020). The Impact and Countermeasure Analysis of New Coronary Pneumonia Epidemic on Small and Medium-Sized Enterprises. Chinese Service Science and Management, 9, 126-138. https://doi.org/10.12677/SSEM.2020.93018

Liu, T., Pan, B., \& Yin, Z. (2020). Pandemic, Mobile Payment, and Household Consumption: Micro-Evidence from China. Emerging Markets Finance and Trade, 56, 2378-2389. https://doi.org/10.1080/1540496X.2020.1788539

Lo, Y. L., Li, Y., \& Chan, K. C. (2019). Contemporary Innovation in China. The Chinese Economy, 52, 387-399. https://doi.org/10.1080/10971475.2019.1617925

Lu, J., Gu, J., Li, K., Xu, C., Su, W., Lai, Z. et al. (2020). COVID-19 Outbreak Associated with Air Conditioning in Restaurant, Guangzhou, China, 2020. Emerging Infectious Diseases, 26, 1628-1630. https://doi.org/10.3201/eid2607.200764

Margetis, G., Grammenos, D., Zabulis, X., \& Stephanidis, C. (2013). iEat: An Interactive Table for Restaurant Customers' Experience Enhancement. In C. Stephanidis (Ed.), Communications in Computer and Information Science (pp. 666-670). Berlin: SpringerVerlag. https://doi.org/10.1007/978-3-642-39476-8_134

Mosler, H. J. (2012). A Systematic Approach to Behavior Change Interventions for the Water and Sanitation Sector in Developing Countries: A Conceptual Model, a Review, and a Guideline. International Journal of Environmental Health Research, 22, 431-449. https://doi.org/10.1080/09603123.2011.650156

Nielson (2020). From the Field: Nielsen South Korea Offers Personal Insight on Shopping Trends Amid the COVID-19 Outbreak. https://www.nielsen.com/

Norman, P., Boer, H., \& Seydel, E. R. (2005). Protection Motivation Theory. Predicting Health Behaviour, 81, 126.

Prasetyo, Y. T., Castillo, A. M., Salonga, L. J., Sia, J. A., \& Seneta, J. A. (2020). Factors Affecting Perceived Effectiveness of COVID-19 Prevention Measures among Filipinos during Enhanced Community Quarantine in Luzon, Philippines: Integrating Protection Motivation Theory and Extended Theory of Planned Behavior. International Journal of Infectious Diseases, 99, 312-323. https://doi.org/10.1016/j.ijid.2020.07.074

Ranka, S. (2020). How Corona Virus Could Affect the Culture of Eating Special Reference to Street Food: The New Normal. IOSR Journal of Business and Management (IOSR$J B M), 22,1-7$.

Rogers, Y. (2020). Is Remote the New Normal? Reflections on COVID-19, Technology, and Humankind. Interactions, 27, 42-46. https://doi.org/10.1145/3403586

Rubin, G. J., Amlôt, R., Page, L., \& Wessely, S. (2009). Public Perceptions, Anxiety, and Behaviour Change in Relation to the Swine Flu Outbreak: Cross Sectional Telephone Survey. BMJ, 339, b2651. https://doi.org/10.1136/bmj.b2651

Sadique, M. Z., Edmunds, W. J., Smith, R. D., Meerding, W. J., De Zwart, O., Brug, J., \& Beutels, P. (2007). Precautionary Behavior in Response to Perceived Threat of Pandemic Influenza. Emerging Infectious Diseases, 13, 1307.

https://doi.org/10.3201/eid1309.070372

Sharifirad, G., Yarmohammadi, P., Sharifabad, M. A. M., \& Rahaei, Z. (2014). Determination of Preventive Behaviors for Pandemic Influenza A/H1N1 Based on Protection Motivation Theory Among Female High School Students in Isfahan, Iran. Journal of Education and Health Promotion, 3, 7. https://doi.org/10.4103/2277-9531.127556

Shaw, R., Kim, Y.-K., \& Hua, J. (2020). Governance, Technology and Citizen Behavior in Pandemic: Lessons from COVID-19 in East Asia. Progress in Disaster Science, 6, 100090. 
https://doi.org/10.1016/j.pdisas.2020.100090

Simbolon, R., \& Riyanto, S. (2020). How Retail Survive Against Pandemic of COVID-19: An Insight from Optical Retailer. International Journal of Current Science and Multidisciplinary Research, 3, 124-132.

Szymkowiak, A., Gaczek, P., Jeganathan, K., \& Kulawik, P. (2020b). The Impact of Emotions on Shopping Behavior during Epidemic. What a Business Can Do to Protect Customers. Journal of Consumer Behavior, 2020, 1-13. https://doi.org/10.1002/cb.1853

Szymkowiak, A., Kulawik, P., Jeganathan, K., \& Guzik, P. (2020a). In-Store Epidemic Behavior: Scale Development and Validation. arXiv preprint: 2005.02764.

https://arxiv.org/abs/2005.02764v1

Traveltips. (2020). Safety and Sanitary Protocols-COVID-19. http://traveltipsgye.com/safety-and-sanitary-protocols-COVID19/

Wang, J. (2003). An Enlightenment from SARS on Upgrading Management of Hospitality Industry. Chinese Tourism Tribune, 18, 11-13.

Wen, J., Kozak, M., Yang, S., \& Liu, F. (2020). COVID-19: Potential Effects on Chinese Citizens' Lifestyle and Travel. Tourism Review.

https://doi.org/10.1108/TR-03-2020-0110

Wilder-Smith, A., Freedman, D. O. (2020). Isolation, Quarantine, Social Distancing and Community Containment: Pivotal Role for Old-Style Public Health Measures in the Novel Coronavirus (2019-nCoV) Outbreak. Journal of Travel Medicine, 27, taaa020. https://doi.org/10.1093/jtm/taaa020

Wong, L. P., \& Sam, I. C. (2010). Temporal Changes in Psychobehavioral Responses during the 2009 H1N1 Influenza Pandemic. Preventive Medicine, 51, 92-93.

https://doi.org/10.1016/j.ypmed.2010.04.010

Wu, J. (2020). The Impact of COVID-19 on Catering Industry and Changes of Marketing Strategies. Chinese Management \& Technology of SME, 7, 110-111. 